\title{
Perioperative Point of Care Cardiac Ultrasound for Anesthetists
}

\author{
${ }^{1}$ Goverdhan D Puri, ${ }^{2}$ Neeti Dogra
}

How to cite this article: Puri GD, Dogra N. Perioperative Point of Care Cardiac Ultrasound for Anesthetists. J Perioper Echocardiogr 2017;5(2):39-41.

\section{Source of support: Nil}

\section{Conflict of interest: None}

"Every work has to pass through three stagesridicule, opposition and then acceptance."

$$
\text { -Swami Vivekananda }
$$

The practice of perioperative transthoracic cardiac ultrasound for patient management in noncardiac surgery faces two polar views. One view is that misdiagnosis by cardiac ultrasound could lead to patient harm, and the best way to avoid that is to ensure that only cardiologists/ sonographers who are experts in performing and interpreting cardiac ultrasound are allowed to practice. ${ }^{1}$ Access to cardiac ultrasound may be variable, and most facilities may have a prolonged waiting time due to high demand and reduced availability of the cardiologist, and this may potentially interfere with surgical work flow. ${ }^{2}$ The alternative view is that clinical diagnosis is frequently incorrect as compared with echocardiography and that ultrasoundassisted examination will reduce the incidence of incorrect diagnosis compared with physical examination alone. ${ }^{1}$

The word FoCUS, as defined by the American Society of Echocardiography, is a "focused examination of the cardiovascular system performed by a physician using ultrasound as an adjunct to the physical examination to recognize specific ultrasonic signs that represent a narrow list of potential diagnoses in specific clinical settings." 3 Various terms/acronyms have been used to describe ultrasound-based bedside protocols, notable among them being FATE, FAST, RUSH, HART Scan, FICE, FoCUS, etc., each having a different scope. ${ }^{1}$ This article will use the term FOCUS (focused cardiac ultrasound)

\footnotetext{
${ }^{1}$ Professor and Head, ${ }^{2}$ Assistant Professor

1,2Department of Anesthesia and Intensive Care, Postgraduate Institute of Medical Education and Research, Chandigarh India

Corresponding Author: Goverdhan D Puri, Professor and Head Department of Anesthesia and Intensive Care, Postgraduate Institute of Medical Education and Research, Chandigarh, India e-mail: gdpuri007@hotmail.com
}

as a generalized term used to describe bedside cardiac ultrasound for patient management in the perioperative period, its indications, limitations, training requirements, and maintenance of competence in trainees.

The term FOCUS essentially is a simplified, limited, problem-oriented, repeatable, qualitative bedside cardiac ultrasound performed by the physician at the point of care. Point-of-care cardiac ultrasound is a reliable tool as compared with comprehensive echocardiography. ${ }^{4}$ Estimation of global ventricular function, presence of pleural or pericardial effusions, and valvular function (excluding aortic stenosis) can be readily done using point-of-care cardiac ultrasound. ${ }^{4}$

The term FOCUS differs from comprehensive echocardiography as the latter has no restriction of scan numbers and views, can make quantitative diagnosis using fully functional echocardiography platforms, and requires advanced sets of skills and training in echocardiography. ${ }^{5}$ The recommendations from the American Society of Echocardiography state that ultrasound equipment used for FoCUS examinations should meet five basic criteria: (1) A transducer with frequency appropriate for adult patients (typically 2-6 MHz), (2) minimal display requirements that include the ability to label images with at least two patient identifiers, as well as the date and time the examination was performed, (3) markers to indicate scale or image depth, (4) two-dimensional gray-scale imaging and ability to adjust depth and gain, and (5) the ability to store images in a retrievable location in the Digital Imaging and Communications in Medicine format. ${ }^{2,6}$ The term FOCUS is thus limited by (1) functionality of its equipment, (2) lack of quantitative data, and most importantly by (3) experience and skill of the performing physician. ${ }^{5}$

Several specialties, such as General Medicine, Emergency Medicine, and Critical Care Medicine have already acknowledged the use of ultrasound and have incorporated ultrasound education into formal training programs. ${ }^{7}$ Royse et $\mathrm{al}^{8}$ evaluated the training course used to teach the heart scan goal-focused transthoracic echocardiography (TTE) study on interpretation of pathology using recorded videos and found a high agreement with course students and experts. Importantly, there are no studies in which clinical examination outperformed echocardiography. The skills required to perform FOCUS can be obtained by noncardiology physicians with limited 
training. Among them, anesthetists have the required ultrasound equipment, knowledge, and facilities for rapid incorporation of skills. Cowie and Kluger ${ }^{9}$ demonstrated that echocardiography-naïve anesthesiology trainees could rapidly and successfully be trained to recognize clinically significant aortic stenosis using TTE.

There is scanty information regarding establishment of training programs in FOCUS. As a prologue to further discussion, it is imperative to define training in respect to cardiac ultrasound. Training is the supervised acquisition of knowledge and technical skills by the learner to perform echocardiography to a predefined standard of competence. ${ }^{10}$ The design of any TTE training program needs to incorporate the technical and analytical skills acquisition.

Anesthesia curriculum in India does not currently specify a requirement for any echocardiography training. There is also a significant lack of both trainers and resources for delivery of training. The training of cardiac anesthesia residents in perioperative point-of-care cardiac ultrasound has led to changes in preoperative diagnosis and surgical management, leading to better patient outcomes. ${ }^{11-14}$ This has also created a better environment for "learning while doing" for these residents. Extending this learning to perioperative caregiver caring for noncardiac surgical patients has also led to better patient outcomes. ${ }^{15-18}$ The anesthesia residents usually have access to ultrasound platforms, because of the current practice of ultrasound-guided central venous and arterial access, ultrasound-guided regional nerve blocks, ultrasound-guided gastric volume, and optic nerve sheath and airway measurements. Thus, the only necessity at the moment is a training program in perioperative point-of-care cardiac ultrasound for hemodynamic assessment.

One of the suggested point-of-care cardiac ultrasound training schedules envisages an educational course for anesthesia residents to be covered over a fixed time period with online resources, didactic lectures, and simulation. The online resources may be used for review of echocardiographic images and loops. The training program must be followed by a postprogram assessment. The program should focus on having a minimum number of image acquisitions and interpretations before the candidates are allowed to appear for the exit exam. Once the teaching sessions have been completed, the trainees should be able to perform, capture, and interpret independent scans, which also need evaluation and validation. Finally, the trainees should prove and maintain competency. The follow-up program posttraining should review the cardiac ultrasound scans performed at intensive care units and various other perioperative areas for a specified period by the course supervisors. Continued professional development can also be assured by attendance of the participants in various echocardiography conferences/ exams as conducted by the Society of Cardiovascular Anesthesiologist (USA) and British Society of Echocardiography (BSE) and Indian Society of Echocardiography and Society of Transesophageal Echocardiography in India (STE). The STE has trained anesthetists, physicians, and intensivists in transesophageal echocardiography (TEE) through its regular TEE workshops and handson courses and is thus involved in promoting the cause of cardiac ultrasound among anesthetists, physicians, and critical care specialists (www.teepgi.org). There has been considerable adoption of cardiac ultrasound within cardiac anesthesia and critical care practice. To this end, effective systems of training have been established. There is, therefore, considerable expertise available to roll out a training program of cardiac ultrasound to a wider group of anesthetists caring for geriatric/cardiac patients for noncardiac surgeries, which is the need of the hour.

\section{REFERENCES}

1. Royse CF, Canty DJ, Faris J, Haji DL, Veltman M, Royse A. Core review: physician-performed ultrasound: the time has come for routine use in acute care medicine. Anesth Analg 2012 Nov;115(5):1007-1028.

2. Canty DJ, Royse CF, Kilpatrick D, Bowman L, Royse AG. The impact of focused transthoracic echocardiography in the pre-operative clinic. Anaesthesia 2012 Jun;67(6):618-625.

3. Spencer KT, Kimura BJ, Korcarz CE, Pellikka PA, Rahko PS, Siegel RJ. Focused cardiac ultrasound: recommendations from the American Society of Echocardiography. J Am Soc Echocardiogr 2013 Jun;26(6):567-581.

4. Andersen GN, Haugen BO, Graven T, Salvesen O, Mjølstad OC, Dalen H. Feasibility and reliability of point-of care pocket-sized echocardiography. Eur J Echocardiogr 2011 Sep;12(9):665-670.

5. Coker BJ, Zimmerman JM. Why anesthesiologists must incorporate focused cardiac ultrasound into daily practice. Anesth Analg 2017 Mar;124(3):761-765.

6. Via G, Hussain A, Wells M, Reardon R, ElBarbary M, Noble VE, Tsung JW, Neskovic AN, Price S, Oren-Grinberg A, et al; International Liaison Committee on Focused Cardiac UltraSound (ILC-FoCUS); International Conference on Focused Cardiac UltraSound (IC-FoCUS). International evidence-based recommendations for focused cardiac ultrasound. J Am Soc Echocardiogr 2014 Jul;27(7):683.e1-683.e33.

7. Fagley RE, Haney MF, Beraud AS, Comfere T, Kohl BA, Merkel MJ, Pustavoitau A, von Homeyer P, Wagner CE, Wall MH; Society of Critical Care Anesthesiologists. Critical care basic ultrasound learning goals for American anesthesiology critical care trainees: recommendations from an expert group. Anesth Analg 2015 May;120(5):1041-1053.

8. Royse CF, Haji DL, Faris JG, Veltman MG, Kumar A, Royse AG. Evaluation of the interpretative skills of participants of a limited transthoracic echocardiography training course (H.A.R.T. scan course). Anaesth Intensive Care 2012 May;40(3):498-504. 
9. Cowie B, Kluger R. Evaluation of systolic murmurs using transthoracic echocardiography by anaesthetic trainees. Anaesthesia 2011 Sep;66(9):785-790.

10. Sharma V, Fletcher SN. A review of echocardiography in anaesthetic and peri-operative practice. Part 2: training and accreditation. Anaesthesia 2014 Aug;69(8):919-927.

11. Liora $Y$, Wells C, Subramaniam S. Preinduction focused transthoracic echocardiography by anesthesiologists in cardiac surgical patients: "checks and balances" approach improves patient care! J Perioper Echocardiogr 2017 Jan-Jun;5(1):1-2.

12. Eltzschig HK, Rosenberger P, Loffler M, Fox JA, Aranki SF, Shernan SK. Impact of intraoperative transesophageal echocardiography on surgical decisions in 12,566 patients undergoing cardiac surgery. Ann Thorac Surg 2008 Mar;85(3): 845-852.

13. Ganesan R, Kumar B, Munirathnam GK, Bhat I, Mahajan S. Modification in surgical plan following intraoperative detection of co existent right atrial thrombus by transesophageal echocardiography in chronic constrictive pericarditis. J Perioper Echocardiogr 2017 Jan-Jun;5(1):34-37.
14. Kumar S, Kumar A, Dutta V. Unusual embolisation of atrial septal defect device in left ventricle and its successful retrieval. J Perioper Echocardiogr 2016 Jul-Dec;4(2):67-69.

15. Kratz T, Steinfeldt T, Exner M, Dell Orto MC, Timmesfeld N, Kratz C, Skrodzki M, Wulf H, Zoremba M. Impact of focused intraoperative transthoracic echocardiography by anesthesiologists on management of hemodynamically high risk noncardiac surgical patients. J Cardiothorac Vasc Anesth 2017 Apr;31(2):602-609.

16. Jorgensen MR, Juhl-Olsen P, Frederikson CA, Sloth E. Transthoracic Echocardiography in the perioperative settings. Curr Opin Anesthesiol 2016 Feb;29(1):46-54.

17. Subramaniam K. Practice of transthoracic echocardiography by anesthesiologists - focused, limited or comprehensive. J Perioper Echocardiogr 2016 Jan-Jun;4(1):1-2.

18. Boisen ML, McHugh SM, Boretsky RH, Phillips DP, Meng L, Caldwell MW, Kaynar AM, Subramaniam K. Perioperative echocardiographic diagnosis of regional wall motion abnormalities: not all of them are ischemic. J Perioper Echocardiogr 2016 Jul-Dec;4(2):70-73. 